\title{
BIIR SANAT FORMU OLARAK DIJITAL OYUN
}

\author{
Dr. Öğr. Üyesi Özge SAYILGAN*
}

\section{ÖZET}

Etkileşimli medyanın kültür endüstrisine eklemlenmiş bir biçimi olarak gelişen ve gündelik yaşamda eğlence kültürüyle ilişkisi içinde yaygınlaşan dijital oyunların sanat alanı içinde düşünülmesi kuramsal düzeyde farklı bir tartışmayı başlatmış oldu. Dijital medyanın bir parçası olan dijital oyunlar dijital ve etkileşimli sanatın bir biçimi veya aracı olarak yeniden kurulabilir miydi? Bu tartışma 'büyük' oyunlarm kitleselleştiği ve endüstri tarafindan önerilen tür ve kahplara sıkıştı̆̆ bir dönemde üretilmeye başlanan bazı 'küçük' oyunların eleştirel, alternatif, sanatsal ve bağımsı gibi tanımlarla kategorilendirilmesi ve deneyimlenmesi ile birlikte devam etti. Bu araştırmanın odağında dijital oyunların sanat alanı ile kurduğu ilişkilerin belirlenmesi, sinıflandırılması ve kristalize edilmesi amacı yer almıştır. 'Dijital oyun sanat mıdır, yoksa değil midir' tartışmasının ötesinde bu ilişkinin nitelikleri irdelenmiştir. Dijial oyun medyasını sanat yapıtı veya deneyiminin bir parçası olarak kullanan sanatçılar; var olan bir dijital oyuna donanım ve/veya yazılım düzeyinde müdahale ederek dönüștüren / yapı-bozan ve etkileșimli veya etkileşimsiz 'oyun sanatı' üreten sanatçılar ve doğrudan 'sanat oyunu' üreten sanatçı/ tasarımcı veya kolektifler oyun ile sanat ilişkisinin üç farklı ayağı olarak bulgulanmıştır. Araştırma 'sanatsal bir ifade aracı olan' ve doğrudan 'bir sanat formu olan' dijital oyun yapıtların da birbirinden ayırarak dijital oyun eğer bir sanat ise bu sanatın dilini oluşturan estetik kategorilerin neler olabileceğini tartışmaya açmıştır.

Anahtar Sözcükler: Dijital, Oyun, Sanat, Etkileşimlilik, Medya 


\title{
DIGITAL GAME AS AN ART FORM
}

\author{
Assist. Prof. Dr. Özge SAYILGAN*
}

\section{ABSTRACT}

Consideration of digital games developed as a form of interactive media articulated to cultural industry and pervaded in daily life with its relation to entertainment culture in an art space initiated a theoretical discussion. Was that possible to reconstruct digital games, a part of digital media, as a tool or form of digital and interactive art? This discussion was prolonged in an era where 'big' games were massified and categorized by industrial genres, with the experience of some 'small' games described and categorized as critical, alternative, artistic or independent. This research focused on determination, classification and crystallization of the existing relations between games and art. Beyond 'Are digital games art or not' discussion, qualities of this relation are analyzed. As a result, artists using digital game medium as a part of their artwork or experience; artists producing interactive or non-interactive 'game art' transforming/de-constructing by modifying an existing digital game's software and/or hardware and artist / designer or collectives producing directly 'artgames' are founded. Separating digital game works as 'a tool for artistic expression' and works as 'an art form' from each other, this research comes up for discussion the aesthetical categories which constitute the language of this new art, when we accept digital games as an artform.

Keywords: Digital, Game, Art, Interactivity, Media 


\section{GİRiş}

Kültür endüstrisinin içine eklemlenmiş bir biçim olan dijital oyunların sanat olarak kabul edilip edilemeyeceği önemli olduğu kadar tarihsel açıdan da ilginç bir tartışma konusu haline gelmiştir. John Lanchester 'Is It Art?'başliklı yazısında (2009) bu sorunu gündeme getirir ve tüm diğer medyayı genel kültürel söylemin içinde sayarken, dijital oyunların oyuncularıla birlikte özerk bir kategori içinde yerleştirildiğini belirtir. Lanchester'ın deyimiyle bu 'kültürel ayrım' dijital oyunların izleyicisi ile izleyicisi olmayan kitlenin arasındaki çok net ve keskin olan ayrımdan kaynaklanmaktadır.Dijital oyun oynamayan kitle için dijital oyunların var olmadığından yola çıkarak, çoğunluk için oyun oynamanın rekabete dayalı bir eylem alanı içinde eğlenceyi çağrıştırdığını ileri sürer.

$\mathrm{Bu}$ incelemede Lanchester (2009) ekonomik bakış açısından dijital oyunların İngiltere'de müzik ve video endüstrisini geride bıraktığ 1 bir dönemde bu soruyu sorduğunu vurgular. Buna karşın Lanchester’a göre, hiçbir medya dijital oyunlar kadar kültürel ayrımcilığa uğramış değildir. Kitaplar, filmler, TV, dans, tiyatro, müzik, resim, fotoğraf, heykel, bu ifade alanlarının hepsi var olan kültürel söylemin içinde (ve ana akım yayınlarda) yer alırken, dijital oyunlar sanat kulübünün dışında tutularak ayrı bir özerk alana sıkıştırılır. Onları oynayanlar ve oynamayanlar vardır ve oynamayan daha geniş kitle için oyunlar en basit ifadesiyle 'yok'tur. (Lanchester, 2009). Dahası ana akım medyada, özellikle de basın-yayın ve TV'da dijital oyun medyası şiddetle, asosyallikle ve sanatla yakından uzaktan ilgisi olmayan daha birçok olumsuz nitelikle peşinen ilişkilendirilir durur ve böylece kültürel ve toplumsal alanın dışında tutulması daha da kolay hale gelir. Bununla birlikte Lanchester’a göre, oyunların sanata yaklaşması, detaylı dünyalarıyla tasarımsal değerleri kadar, bu hayali dünyalarda oyuncuya sunulmuş özgürlükle de ilişkilidir (2009).

Ernest Adams da oyun endüstrisinin büyük bir bölümünün sanat değil, popüler kültür ürettiğini ve oyunların büyük bir bölümünün sadece eğlence için yaratıldığını belirtir (akt. Robles, 2014) Adams’a göre,

"Sanat sanat galerilerinde sanat uzmanları tarafından satın alınır, sanat eleştirmenlerince eleştirilir ve sanat müzelerinde korunur. Milyonlarca insan için büyük sayılarda üretilip Toys' $R$ Us’da 59.95 Dolar’a satılmaz. Fakat yaptığımızın büyük bölümünün popüler kültür olduğu gerçeği etkileşimli ortamın bir sanat formu olmasının önüne geçemez" (Adams, 2006).

Adams'ın da sinema sanatı bağlamında vurgulamış olduğu gibi, sanat tarihi dijital oyunlardan önce, özelliklede mekanik olarak yeniden üretilebilir olan kitlesel medyanın yaygınlaşmasıyla fotoğraf ve film için de benzer tartışmalara sahne olmuştur. Aslında her 'yeni medya' içine doğduğu dönemin egemen medyası tarafından öncelikle kuşkuyla karşılanmıştır. Örneğin, belleğe dayalı metin üretiminin merkezde olduğu birincil sözlü kültür döneminde (Ong, 2007) yazı insan belleğini zayıflatacak bir teknolojik uzantı olarak endişe yaratmış, sinema ilk olarak alt-sınıfa ait avam bir eğlence olarak görülmüş, sesin sinemaya girişiyle ise artık sinemayla sanat yapılamayacağı, sinema oyunculuğunun yok olacağı bile düşünülmüştür.

Hareketli görüntüyü mümkün kılan bir aygıt olarak sinematografın icadıyla sinemanın ye- 
dinci sanat olarak kabul edilmesi arasında geçen zamanda sinemanın kendi dilini keşfetmesi ve bu araç ile sanatsal bir ifade alanı yaratılabildiğini göstermesi gerekmiştir. Sanat sınıfına kabul edilmeden önce panayır eğlencesi olarak görülen sinema kısa sürede kar getiren bir endüstri haline gelmiş; aynı zamanda kentlerde biriken ve işgücünü oluşturan kalabalıklar için de kültürel bir harç görevi görmüştür. Üstelik sinema birbirinden farklı kültür ve dillere sahip bu kalabalıklar için ortak bir mit üretme aracına dönüşmüş, kitleleri bir arada tutacak ortak kültürel harcı ve kültürel belleği oluşturmada işlev görmüştür. Sinemanın modern kent içinde yabancılaşmış insanlar için yaptığını, elbette Internet'in yardımıyla, küreselleşmiş bir dünyanın bireyleri arasında gerçekleştirilmesine katkıda bulunan dijital oyunların ilk biçimleri de, tarihsel olarak Soğuk Savaş Dönemi’ndeki silahlanma ve uzaya çıkma yarışının bir ürünü olarak bilim insanları tarafından bilimsel laboratuarlarda üretilmiştir. Fakat 20 yıl gibi kısa bir sürede oyun teknolojisinin ve etkileşimli ortamın ticari potansiyelleri keşfedilmiş oyunların kültür endüstrisi ürünü olarak yeniden düşünülmesi ve tasarlanması söz konusu olmuştur. Teknolojilerinin üretildiği dönemin tarihsel ve toplumsal koşulları dolayısıyla kapitalist üretim - tüketim döngüsünden uzak kalması düşünülemeyecek dijital oyunların sinemanın tarihsel gelişimiyle bu türden bir benzerlik taşıması ilginçtir. Fakat yine de bir farkla: Sinema özellikle I. ve II. Dünya Savaşları arasında daha çok kitleselleştirmek için işlev görmüştür. Dijital oyunların kültür endüstrisine katılması ise Soğuk Savaş sonrasında küreselleşme döneminde gerçekleşmiş ve geç kapitalizmin daha bireyselleşmiş insanları, "küresel köyün" sakinleri için ekrandaki metni kişiselleştirme önerisiyle gelen etkileşim olanağını sunarak başka bir toplumsal arkaplana yerleşmiştir.

Gerçekten de dijital oyunların bilimsel laboratuarlardan çıkması ve kültür endüstrisi ürünlerine dönüşümünün yaşandığ 1972 yılında, bu yeni medya hem arcade oyun makineleri biçiminde kamusal alanda, hem de Magnavox Odyssey ismiyle ev konsolu biçiminde evlerin salonunda, televizyonun hemen yanında yerini alır (Brisbois, 2007). Bu noktadan sonra izleyicinin etkileşimciye dönüşme talebine karşlık vermeye başlayan ve gün geçtikçe hem teknolojisi hem de içerikleriyle sürekli gelişime açllan dijital oyun; kültürel endüstrinin önemli çarklarından biri haline gelir. Fakat burada sorulması gereken esas soru, endüstriyel büyüklüğü sonunda sinemayı da geride bırakan dijital oyunların geniş ticari potansiyelleri ve özerk bir oyuncu kitlesi tarafından tüketiliyor olmaları, onları sanatsal bir ifade alanı olmaktan alıkoyabilir mi? Ve elbette nihayetinde, dijital oyunlar sanat olarak kabul edilebilir mi?

\section{DİJITAL OYUN VE SANAT TARTIŞMALARI}

Tartışma 2012 yılında New York Modern Sanatlar Müzesi'nin, içinde dijital oyunların bulunduğu bir koleksiyonu sergileyeceğini duyurmasıyla önem kazandı. Sergilenecek oyunlar içinde dijital oyun tarihinde aynı zamanda önemli ticari başarılar kazanmış ve oyunların yaygınlaşmasında ve kitleselleşmesinde rol oynamış Pac-Man (1980), Tetris (1984), The Sims (2000) gibi endüstriyel ürünler olarak da tanımlanabilecek oyunlar yer almaktaydı. (Antonelli, 2012). Fakat dijital oyunların yeni bir sanat kategorisi olarak çağdaş sanat koleksiyon ve sergilerinde yer almalarından önce de oyunların sanat olup olmadığı tartışması gündemdeydi. 
Jack Kroll Mart 2000'de Newsweek'teki bir yazısında, oyunların eğlenceli ve pek çok açıdan ödüllendirici olduğunu fakat bir sanat yapıtı sayılamayacağını çünkü oyunların duygusal karmaşayı aktaramayacağını savundu. Kroll’a verilen pek çok tepki içinde akademiden bir eleştiri Henry Jenkins tarafından geldi. Jenkins, 'Dijital Çağın Sanat Biçimi' başlıklı yazısıyla Kroll'u dijital oyunların potansiyelini anlayamamakla eleştirdi (akt. Smuts, 2005). Jenkinse (2000) göre, oyunlar makine çă̆ında ortaya çıkan her öncül medya gibi dijital çağa özgü yeni ve yaşayan bir sanat türüdür (a new lively art); oyunlarla ilişkilendirilen tüm olumsuz niteliklere karşın, bilgisayar oyunları der Jenkins, sanattır - popüler sanattır, gelişmekte olan, çoğunluk tarafından onaylanmamış bir sanattır, fakat yine de sanattır. Çünkü oyunlar, yeni estetik deneyimler açar ve bilgisayar ekranını kapsamlı bir biçimde erişilebilir deneyim ve yenilik alanına dönüştürürler.

Kroll'un dijital oyunları sanat kulübünün dışında tutan görüşüne benzer bir görüş Ebert tarafından 2010 yılında yeniden gündeme getirildi. Ebert de dijital oyunların diğer sanat yapıtları gibi oynanmak üzere tasarlandığını ve asla sanat olarak kabul edilemeyeceğini ileri sürdü. Ebert’e göre (2010) sanat ve oyunlar arasındaki en açık fark oyunu kazanabileceğimiz gerçeğidir. Oyunun kuralları, puanları, amaçları ve sonucu bulunur. Buna göre sanat kazanılmaz, sadece deneyimlenir. (akt. Sezen, 2013).

Chris Crawford (1997, s.127) ise, oyun tasarımını öncelikli olarak sanatsal bir süreç olarak tanımlar. Fakat bu süreç aynı zamanda teknik bir süreçtir. Bir oyun tasarımcısı oyun geliştirirken biri sanatsal dünya diğeri teknik dünya olmak üzere aynı anda iki ayrı dünyada yaşamak durumundadır. Bir yığın kod arasında kaybolsa da büyük sanatsal amaçlarını izlemek durumundadır. Kendisi de bir oyun tasarımcısı olan Crawford’a göre, her sanat biçimi fiziksel bir ortam aracılığıyla ifade alanı bulur. Sanatçının kendini ifade edebilmesi için öncelikle bu fiziksel ortamın kontrolü ve manipülasyonunda teknik olarak ustalaşması gerekir. Heykeltraşın mermerin veya çalıştığı diğer malzemelerin sınırlarını tanıması, ressamın resim teknolojisini ve ışığın davranışını tamamıyla anlaması, müzisyenin ses tasarım teknolojisinin derinliklerine inmesi gibi bilgisayar oyunu tasarımcısının da çalıştığı ortamın kendisine sunduğu olanak ve sinırları tanıması gerekir ( Crawford, 1997, s.102).

Sanat ve oyun deneyimlerinin karşılaştırmasını yapan Folkerts (2010) sanat, estetik ve sanatsal kavramlarının sıklıkla birbirinin yerine ve yanlış bir biçimde kullanıldığını vurgular. Üstelik sanatın tanımı ve işlevi zamandan zamana değişiklik gösterir. Folkerts'in vurgusu öncelikle sanatın anlamını netleştirmeye yönelir; çünkü bir oyun tasarımcısı veya eleştirmeni oyun sanattır dediği zaman genellikle el hünerini ve estetik yüceliği veya oyuncuya estetik deneyimler sunan görkemli sanal çevreyi kastetmektedir. Fakat "sanat hiç de güzel olmak zorunda değildir - modernizm ve postmodernizmden beri kabul gören bir bakış açısıyla: sanat öncelikli olarak ifade gücüyle ilgilidir (...) Çağdaş sanat yaklaşımları açıkça sanat deneyimine temel bir rol yüklerler. Sanatsal olan, yapının (artefact) içkin nitelikleriyle mutlaka tanımlanmaz, fakat kendisinden edinilen kavrayış ve algıyla konumlandırılır” (Folkerts, 2010, s.100-102). Buna göre sanatsal deneyim, sanattan etkileşimcinin (izleyici-oyuncu) kişisel deneyimine göre yeniden tanımlanabilmesiyle farklılaşır. Bu bağlamda, etkileşime giren bir oyuncunun oyun metniyle olan bireysel ve eşsiz deneyimi onun oyundan edindiği kavrayış ile birleşerek oyun oynama deneyimini sa- 
natsal bir deneyim haline getirebilir. Burada, oyun metninin oyuncuya sunduğu özgürlük alanı ve seçim yapma yetkesi genişledikçe ve oyunun sinırları belirsizleştikçe, oyun metni açık yapıt olarak kendini sunar ve kişisel/sanatsal deneyim alanı da genişler.

Folkerts (2010, s.102) sanatsal deneyim ile estetik deneyimi birbirinden net bir biçimde ayırmayı önerir: Estetik deneyim genellikle güzel olan ile ilişkilendirilirken, sanatsal deneyim hiç de hoş bir deneyim olarak gerçekleşmeyebilir. Sanatsal deneyimler genellikle içeriğe, sanat yapıtının iletişimini üzerine kurduğu iletilere ve anlama bağlıdır. İçerik ve anlam ise kendi estetik biçimlenmesinden bağımsız değildir. Sanatsal deneyim içeriğin ne olduğuyla, estetik deneyim ise nasıl olduğuyla ilişkilidir. İçkin anlam, biçimi ve onun kendini dişavurduğu dili de sorunsallaştırabilir, ve dönüşüme uğratır. Folkerts'in (2010) bir ayrımlama girişimi de sanatsal deneyim ile eğlence deneyimi arasındadır: Eğlence deneyimi popüler Hollywood sineması veya soap opera izleme deneyimindekine benzer bir biçimde izleyicisinden güçlü bir anlamlandırma süreci talep etmez. Bu türden bir izleme ediminde yapı(t) kapalıdır ve anlam olabildiğince sabit ve sınırlıdır. Folkerts bu türden bir izleme deneyimini çağıran yapı(t)ları birinci dereceden temsil olarak tanımlar. Sanatsal deneyimi eğlence deneyiminden ayıran en temel süreç çok katmanlı anlamlandırma talebidir. Folkerts'in tanımıyla ikinci dereceden temsil olarak sanat yapıtı, birincil, sabit ve kapalı anlamın dışında bireysel okumalarla da yeniden yapılanmaya açık bir etkileşim deneyimini çağırır.

Dijital oyunların bir sanat formu olarak algılanmasında eğlence ve sanat deneyimlerinin karşılaştırılması bağlamına yer veren Robles (2014) ise her sanat biçiminin aslında eğlenceyle bir bağı olduğunu ileri sürer. Ayrıca Robles’e göre, sanatsal deneyim sunan oyunlar, tarihteki pekçok edebi ve sinemasal yapıtın sağladığı gibi, fakat sadece kendine ait bir aracı, etkileşimliliği kullanarak, düşünce iletimine yol açabilir. Sanatsal ifade alanı olarak sinemanın dilini oluşturan çekim ölçekleri, kamera hareketleri, kurgu ve mizansen gibi öğeleri de kapsayan fakat bunlardan farklı ve ayrıca öykü içeriğinden bağımsız olarak dijital oyun mecrasının ifade dilinin merkezinde etkileşimlilik yer alır. Buradan yola çıarak dijital oyun ile sanatsal bir deneyim yaratmak isteyen bir tasarımcının etkileşimliliğin doğasını anlaması, onu sorunsallaştırması, dönüştürmesi veya bir bağlam içinde yeniden üretmesi beklenebilir. Yapıtın diğer tarafından bakarsak dijital oyun içinde sanatsal bir deneyim yaşamak isteyen etkileşimcinin, bu deneyimi öykü içeriğinden, estetik inşadan ve sinema, edebiyat, müzik gibi diğer sanat dillerinin karmaşık bütünlüğünün dışında, sadece oyuna özgü bir araç olarak etkileşimli yapının kullanımında araması beklenmelidir. Ayrıca söz konusu etkileşimli yapının Folkerts'in tanımıyla birinci dereceden anlam üretiminin dışında bir anlam üretimine açık olup olmadığı; oyuncunun eğlence işlevinden bağımsız olarak (çünkü oyuncu sanatsal bir deneyim yaşarken eğleniyor olabilir de olmayabilir de), ikincil dereceden anlam okumalarına yönelip yönelmediği de oyun deneyimini sanatsal olarak tanımlamada yardımcı olacaktır.

Dijital oyunları sanatsal bir ifade aracı olarak tartışmaya açan ve dijital oyunların "sanatsal ifade noktasındaki özgün yönünün prosedüral temsili bir ifade aracı olarak kullanılmaları”na bağlayan Sezen (2013, s.129) MoMẢnın 2012 yılında resmi sitesinde duyurmuş olduğu içlerinde Pac-Man (1980), Tetris (1984), Myst (1993), The Sims (2000) gibi ticari başarı elde et- 
miş oyunların da bulunduğu 14 dijital oyundan oluşan bir koleksiyonun sergilenmesine ilişkin detaylı duyuru metnini gündeme getirir. Antonelli (2012) tarafından kaleme alınan ve dijital oyunların kesinlikle sanat olduğunu ileri süren yazıya karşı yazılan eleştiriler de elbette bu tartışmanın bir parçasıdır. Örneğin İngiliz The Guardian gazetesinde yazan sanat eleştirmeni Jonathan Jones (2012) Antonelli’nin yazısının hemen arkasından "Üzgünüm Moma, Video Oyunları Sanat Değildir” başlıklı yazısında Pac-Man ve Tetris gibi oyunların Picasso ve Van Gogh ile aynı mekânda sergilenmesiyle sanat yapıtı olamayacağını ileri sürerek dijital oyunun sanatla kurulmaya çalışan ilişskisine karşı çıkar (Jones, 2012; akt. Sezen, 2013, s.130).

\section{SANATI TANIMLAMAK}

Aslında neyin sanat alanına kabul edilip edilemeyeceğiyle ilgili olan bu soru, başka bir soruyu gündeme getirir: O halde sanat nedir? Barrett’a (2012) göre sanatın iki tür tanımı vardır. Bunlar yüceltmeci ve sınıflandırmacı tanımlar olarak sayılabilir. Bunlara alternatif olarak sanatın açık tanımı da eklenebilir. Genellikle "bu bir sanat eseri” sözü tanımlanan şeyi yüceltmeyi amaçlar. Bu aslında tanımlanan şeyin kendi türünün en iyisi olduğu üzerine yapılan bir belirlemedir ve aynı zamanda sanat tanımını iyi ve güzel olana da yaklaştıır. Sanatın betimlemeci ve sınıflandırmacı tanımlarına göre ise bir şeyin sanat olarak kabul edilmesi için taşıması gerekli olan niteliklerin belirlenmesi söz konusu olmuştur. Sanat bu tür tanımlamalar içinde kurumsallaşmaya başlar ve sanat nesnesini çevreleyen bir 'sanat dünyası' tanımın içinde yerini alır. Buna göre sanat, sanat kurumlarından, sanat kuramından ve sanat tarihinden bağımsız değildir. Barrett, Arthur Danto’nun sanat tanımındaki tarihsel bağlama verdiği önemi ve George Dickie’nin sanat kurumlarının işlevsel yönlerini gündeme getirmesini örnek verir: Örneğin Dickie’ye göre;

“(1) Bir sanatçı bir sanat eseri yaptığı anlayışına katılan kişidir. (2)Bir sanat eseri sanat dünyası kitlesine sunulmak üzere yaratılmış bir yapıdır. (3) Bu kitle sanat nesnesinin kendisine sunulduğunu farklı derecelerde kavramaya hazır kişilerden oluşur. (4) Sanat dünyası tüm sanat dünyası sistemlerinin bir bütünüdür. (5) Bir sanat dünyası sistemi sanat yapıtının bir sanatçı tarafından sanat dünyası kitlesine sunabilmesi için bir çerçevedir" (Stecker, 2003; akt. Barrett, 2012, s.4).

Bu türden bir sınırlandırma içinde sanat dünyası, küratörler, galeriler, müze ve koleksiyoncular, sanat eleştirmenleri ve tarihçileri ile tüm bunlar arasındaki ilişkilerden bağımsız herhangi bir nesne, sanat olarak kabul edilemez. Danto’ya göre ise,

“(1) X’in bir konusu varsa; (2) X bu konu aracılığıyla bir bakış açısı veya tutum ileri sürüyorsa; (3) retorik (genellikle de metaforik) boşluklar kullanıyorsa; (4) bu boşluklar izleyici katılımı ile tamamlanmaya açıksa (yorumlama) ve (5) yapıt ile yorum birlikte sanat tarihsel bir bağlam gerektiriyorsa; X bir sanat yapıtıdır” (Carroll, 2003; akt. Barrett, 2012, s.5).

Dantơnun sanat tanımı sanat çevresinden ve ilişkilerinden çok sanat nesnesine odaklanarak işlevsel değil kuramsal bir yaklaşımla ve sanat yapıtı ile izleyicisinin etkileşimini sanat tarihsel bağlam içinde düşünerek tamamlanır. 
Barrett sanatın tüm tanımlarının sınırları olduğunu ve zayıflıklara sahip olduğunu vurgulasa da, söz konusu dijital oyunlar olduğunda bu tanımların eksiklikleri veya birbirleriyle olan çelişkili ilişkileri daha da belirginleşir. MoMA’nın koleksiyonuna kültür endüstrisi ürünleri olarak ortaya çımış olan oyunları katması ile sanat dünyasının da bir nesnesi haline gelen oyunlara öncelikle bu sanat çevresinden, örneğin bir sanat eleştirmeninden itiraz gelmiştir. Ne de olsa, bu dijital oyunların üreticileri, sanat çevresi için sanat yapıtı üretmek amacıyla değil, aslında popüler kültür ürünü olarak geniş kitleler için oyun üretme amacıyla yola çıkmışlardır. Örneğin Super Mario’nun yaratıcısı Myamato için önemli olan büyük anne ve torunun aynı anda ve birlikte oynarken keyif alabilecekleri bir oyun tasarlamak olmuştur. Fakat aynı koleksiyonda yer alan örneğin Passage (2007) gibi dijital oyunlar da popüler kültür içinde yaratılmış ve alışılagelmiş kalıplara karşı yeni biçimler önererek, Danto’nun tanımındaki gibi oyuncularına dolduracakları boşluklar sunar, oyun deneyimini sanatsal deneyime yaklaştırırken, dijital oyun endüstrisinin geleneksel biçimlerine karşı koyarlar.

Bununla birlikte Barrett'in (2012) de belirttiği gibi sanat yapma amacıyla yola çıkan sanatçılar da (genellikle bağımsız veya görece daha küçük bütçeli oyun geliştiricileri/ kolektifleri gibi) bazen bu türden sanat tanımlamalarına bilinçli olarak karşı çıkar, sanatın çizilmiş sınırlarını sorunsallaştırır ve kuramsal dogmanın çizdiği ölçütlere karşı direnç gösterirler. Bunun sanat dünyasındaki en belirgin örneği olan Duchamps'in Fountain’i (1917) sanatın ontolojik, epistemolojik ve kurumsal tüm tanımlarını tartışmaya açmıştır: "(1) Sanat nedir? (2) Bir şeyin sanat olduğunu nasıl biliriz? (3) Sanatın ne olduğuna kim karar verir?” (Barrett, 2012, s.6). Bu açıdan bakıldığında; ister sanat çevresinde sanat üreten bir sanatçı olsun, ister bu çevreden uzak bir oyun tasarımcısı olsun, verili sınırları iteleyen, onların ötesine geçmeye ve içinde bulunduğu tanımları sorunsallaştırarak direnç göstererek yeni tanımlar ve biçimler önerisiyle belirli bir muhaliflik çizgisi içinde eylem içinde olan bir kişi ile onun ürettiği nesne veya deneyimin sanat deneyimini çağrıştırdığını söylemek yanlış olmaz. Belki de sanatı tanımlarken bu türden tanımların yarattığı sınırları ve ölçütleri sorgulamanın da bu tanımın bir parçası olması gibi bir öneri ile sanatın daha açık bir tanımına ulaşılabilir. Zaten Barrett’ın da Morris Weitz'den yola çıarak gündeme getirdiği sanatın açık tanımı önermesi bu türden sınırlar ve ölçütler koymaya karşı bir duruştan kaynaklanır. Weitz’a göre sanat yaşayan bir kavramdır ve belirli koşullara bağlanamaz. Sanat bu tür tanımlara çabalarına karşı direnen açık bir kavram olarak tanınmalıdır (Weitz, 1997; akt. Barrett, 2012, s.6).

Eco’ya göre açık yapıt bir önerme poetikasını gündeme getirir. "Bu önerme poetikasıyla yapıt bilinçli olarak okurun tepkisini özgürleştirmeye açık duruma getirilir. "Öneren” yapit her defasında okur-yorumcunun hayal gücünün ve duygularının katkısıyla yeniden yaratılır" (Eco, 2016, s.74). Açık yapıtın poetikası yorumcuyu "bilinçli özgürlük eylemleri” yönünde yüreklendirir, onu yapıtın öngördüğü zorunluluklar tarafından belirlenmemiş, kendi tarzını yarattığı bir sonsuz ilişkiler ağının tam ortasına yerleştirir (Pousseur'den akt. Eco, 2016, s.67). Açık yapıtlar edebiyattan müziğe ve plastik sanatlara dek yorumcusu için belirli bir anlam dizgesi yerine bir olasılıklar evreni sunarak kendini gösterir. Edebiyat alanında James Joyce'un Ulysses adlı eseri okuyucusuna istediği yerden girebileceği bir yapı sunar. Eco’ya göre açık yapıtın zirvesi olarak 
kabul edilebilecek Ulysses’in özellikle "Wandering Rocks" bölümünde yazar pek çok farklı açıdan görülebilen küçük bir evren yaratmış ve "böylece Aristotelesçi poetikanın son kırıntılarıyla birlikte homojen bir mekânda zamanın tek yönlü ilerleyişi kavramı tamamen yok olmuştur” (Eco, 2016, s.75).

Sanatın tanımının zaman içinde sürekli değişkenlik gösteren ve tartışmalı doğasının yanında, sanat ve izleyici arasındaki etkileşim ilişkisi, dijital sanat biçim, tür ve yöntemleri ile bunların çağdaş sanat bağlamı içindeki konumları da tartışmaya yeni boyutlar kazandırır. Bir teknik olarak fotoğrafın bulunması sonrasında sanat ve sanat yapıtı üzerine görüşler nasıl tartışmalı hale geldiyse ve bu tartışmalar eski sanatın ve geleneksel yöntemlerin kendilerini sanat tarihi içinde yeniden sorusallaştırmalarına yol açtıysa; dijital devrim sonrasında yeni teknoloji sanat üretimi için yeni mecralar açmaya başlamış; fakat aynı zamanda sanatın biçim, tür ve yöntemleri üzerine benzer tartışmaları yeniden gündeme getirmiştir. 21. yüzyıl birbiri ardına gelen birçok teknolojik gelişimi karşılamış ve sanat üretimi için yeni malzeme, teknik ve yöntemler de bu gelişmeye eşlik etmiştir. Dijital teknoloji, kendinden önceki film, video, fotoğraf gibi malzemelerle de bütünleşik bir sanatsal ifade alanı açmıştır.

"Geçmişten günümüze sanatsal üretim "geleneksel yöntem", "mekanik yeniden üretim” ve "dijital yöntem” olmak üzere üç aşamada ele alınabilmektedir (...) Ancak, bilgisayar sanatını kabul etmede, başlangıçta geleneksel sanat ve mekanik yeniden üretim toplumları oldukça isteksiz olmuştur. Dijital teknolojinin gelişmesiyle, çağdaş sanat tarihinin geleneksel anlamda, dijital sanat bağlamında uyarlanması zorunlu hale gelmiş, mühendisler, programcılar ve sanatçılar ortak çalışarak sanat ürünlerini yaratmaya başlamışlardır” (Özel Sağlamtimur, 2010, s.216).

Dijital Çağın Sanatı’nın yazarı Wands’a (2006) göre, dijital sanatı oluşturan birçok sanat dalı arasında dijital animasyon ve video, dijital enstalasyon ve sanal gerçeklik, yazılım, veritabanı, net sanatı gibi oyun sanatı da yer almaktadır. Bu dönemde müzeler de dijital sanat sergileri düzenlemeye daha çok ilgi duymaya başlarken, geleneksel sanat koleksiyonlarını da Internet üzerinden yayınlamaya başlamışlardır (Wands, 2006, s.8). Görüntü oluşturmanın dijital teknoloji kullanılarak gerçekleştirilmesi ve önceki formların dijital teknolojiyle yeniden sunulmasının yanında, dijital teknolojiyle bir olanak olarak kullanımı mümkün olan etkileşim unsurunun da yeni bir ifade alanı açması söz konusu olmuştur.

Etkileşim dijital teknolojinin gelişiminden bağımsız olarak, sanatçı, sanat yapıtı ve izleyici ilişkisine çoktan eklenmiş bir unsur olarak zaten çağdaş sanatın önemli bir yöntemi haline gelmişti.

"Bugün, dijital sanat müzelerle galerilerde serpilip gelişmeye devam etmektedir. Dijital sanat, kendisi ve çağdaş sanat arasında algılanan farklılıkların pek çoğu bulanıklaştıkça, yavaş yavaş çağdaş sanat manzarasında yerini almaktadır. Biz bir geçiş dönemindeyiz: Geleceğin sanatçları bilgisayarların olmadığı bir dünyayı asla bilmeyecekler ve bu yüzden onların teknolojiyle yaratılan sanat ile çağdaş sanatın başka türleri arasında bir ayrım yapmaları da mümkün olmayacaktır" (Wands, 2006, s.30). 


\section{SANAT OLARAK OYUN VEYA BİR SANAT MECRASI OLARAK OYUN}

Dijital oyunun sanat dünyası ile olan ilişkisinin bir boyutu, sanatçıların dijital devrim sonrası bu yeni ortamı bir üretim alanı / aracı olarak görüp, sanat yapıtı veya deneyimi üretiminde kullanmaya başlaması ile belirginleşir. Oyunlar, dijital teknolojinin içindeki birçok diğer birimden biri olarak çağdaş sanatçılar için bir üretim teknolojisi olarak durmaktadır. Sezen’e (2013) göre, dijital oyunların güncel sanat çevresi ile karşılaştığı 1990’lı yılların sonuna doğru sanatçların oyunları ilham veren ve işlenebilecek bir malzeme olarak kullandığı oyun sanatı (gameart) hareketi, video sanatı (videoart) hareketi ile benzer özellikler gösterir. Oyunu bir mecra olarak kullanan bu türden sanatçı girişimleri genellikle oyun metninin oyunsallığını törpüler ve onu sonunda oyun olmayan bir sanat yapıtına dönüştürür.

Örneğin sanatçı Alison Mealey, Unrealart (2005) projesini gerçekleştirirken, bilgisayar oyunlarını sanatsal amaçlarla kullanmanın yollarını keşfetmeye çalışır ve oyuncular arasındaki etkileşimlere bakarken, aynı zamanda oyunun oynanışından (gameplay) 'oyun' yönünü almayı ve sonunda oyun olarak kabul edilemeyecek fakat yine de oynaması eğlenceli olacak bir şey yaratmak istediğini belirtmiştir. Sanatçı Unrealart projesini Unreal Tournament (Bleszinski ve Polge, 2004) isimli bilgisayar oyunu üzerine kurmuş, bir grup oyuncunun aynı anda yaklaşık 30 dakika oyunu oynamasını sağladıktan sonra karmaşık çizimler üretebilmek için oyundan oyuncu etkileşimlerine bağlı veriler çekmiştir. Bu çizimler aynı zamanda fotografik portreler üzerine yapılmıştır. Mealey, sanatsal üretim sürecinde hem dijital teknolojiyle birlikte rastlantısal ve oyunsal etkileşim unsurunu, hem de çizim ve fotoğrafı malzeme olarak kullanmıştır. Oyun ve oynanış sanat yapıtının üretim sürecinde seçilmiş mecralar olarak kullanılmıştır. Sanatçı Unrealart’’ sergilemek için, elde ettiği resimlerin büyük baskılarının yanında resmin oluşma sürecini de, dolayısıyla oyun metni ile oynanış durumunu da sergilemeye katmayı düşünmüştür (Petersen, 2005).

Aslında 90’lı yıllar dijital teknolojinin gündelik yaşamın içinde daha yaygın olarak kullanılmaya başlandığı bir dönemdir ve bunun sonucunda sanatçılar da bilgisayar, çeşitli yazılım ve İnternet gibi yeni teknolojileri keşfetmeye başlamıştır. Dijital teknolojilerin çağdaş sanat ve kültürü derinden etkilediğini belirten Wands’a (2006) göre çağdaş sanatçılar İnterneti yeni bir sanat mecrası olarak kullandı ve dijital aletlerle teknikleri kendi yaratım süreçlerinin bir parçası olarak benimsedi. Bir yandan kültürel / yaratıcı endüstrinin yeni mecrası olarak gündelik yaşamda gün geçtikçe yaygınlaşan oyunlar, diğer yandan dijital teknolojiye ilgi duyan sanatçılar için de bir ortam sağlamaya başladı.

Sanatçlar ve oyunlar arasındaki yaratıcı etkileşim Alexander R. Galloway ve Mark Tribe tarafından yaratılan ve kendisi de bir net sanatı projesi olan Rhizome.org tarafından 2001 yılında düzenlenmiş olan ve Massachusetts Çağdaş Sanat Müzesi’nde sergilenen 'Game Show'la iyice gözler önüne serilmiştir. Bu sergide yer alan sanatçılardan Jodi ve Masiej Wisniewski oyun sanatı (gameart), net sanatı ve enstalasyon arasındaki sınırlarda geziniyorlardı. Örneğin Jodi’nin Amerika'daki ilk sergileri olan Eyebeam'deki INSTALL.EXE adlı çalışmasında Quake 1 adlı ticari oyunun 'oyun modları' olarak yeniden üretilmiş olan UNTITLED GAME ve CTRL-SPACE gibi oyunlar yer almıştı (Wands, 2006, s.165-166). 
Oyun modu yapımının bazı biçimleri, oyun metnini farklı düzeylerde dönüştürmeyi amaçlayan ve sanatsal veya eleştirel müdahalelerden oluşabilir. Mod, modification (değiştirme, değişiklik) kelimesinin kısaltılmış karşılığı olarak kullanılır ve Galloway’in (2006) tanımıyla, oyun modu değiştirilmiş oyun veya bir grup veya kişi tarafından şifresi kırılmış (hack'lenmiş) oyun demektir.

Oyun modu yapımı, oyunun verili sınırlarını ve ekrandaki çıktısının altındaki algoritmik düzeyle olan etkileşimi gerektirir. Mod yapımı, aktif oyuncuların oyun diline, ekrandaki görüntünün arkasında işleyen ve aslında kendilerini farklı derece ve biçimlerde yönlendiren algoritmik görünmez yüzeye, yazılıma veya doğrudan donanıma müdahale etmeleriyle gerçekleşir. Mod yapımın farklı düzeyleri bulunur:

“(1) Görsel tasarım düzeyinde, yeni karakter modelleri, yeni aşama haritası eklenmesi vb. (2) oyunun kuralları düzeyinde, oynanışın, kimin kazanıp, kaybettiğinin, oyunsal eylemlerin yarattığı etkilerin değişimi, (3) yazılım teknolojisi düzeyinde, karakter davranışlarının değişimi, oyun fiziği, aydınlatma teknikleri gibi” (Galloway, 2006, s.107).

Örneğin Cory Arcangel I Shot Andy Warhol (2000) adlı oyunu üretirken Nintendo kartuşlarının şifresini kırarak, Hogan’s Alley (Iwatani, 1984) adlı oyunda yer alan karakterlerin yerine kültürel ikonik kişilikleri yerleştirmiştir. Sanatçı yazılımın sınırlarını onları yeniden yazarak değiştirmiş̧tir. (Wands, 2006, s.180). Yapıtın künyesinde kullanılan malzeme olarak 'yeniden programlamış Nintendo Kartuş’ açıklaması dikkat çekicidir. I Shot Andy Warhol, ticari bir oyun olan Hogan's Alley'in (Iwatani, 1984) modu olarak yaratılmıştır ve oynanış ve etkileşim unsuru kaldırılmamıştır. Buna karşın, Arcangel Super Mario Clouds (2002) adlı çalışmasında orijinal Super Mario Brothers kartuşuna doğrudan müdahale ederek, oyunun sadece gökyüzü ve bulutları kalacak şekilde tüm karakter ve diğer mekânsal unsurlar ile etkileşim ve ses öğelerini de kaldırarak değiştirmiştir. Sanatçının kullandığı mecra 'Handmade hacked Super Mario Brothers cartridge and Nintendo NES video game system’ (elle şifresi kırılmış Süper Mario Kardeşler kartuşu ve Nintendo NES video oyun sistemi) şeklinde tanımlanmıştır (Görsel 1).

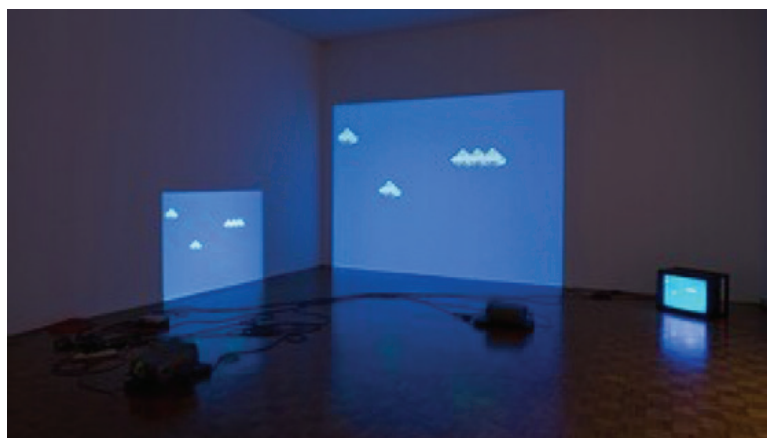

Görsel 1. Arcangel, "Super Mario Clouds", Boyutları Değişken Oyun Enstalasyon, Elle Şifresi Kırılmış Süper Mario Kardeşler Kartuşu Ve Nintendo NES Video Oyun Sistemi, 2002, Whitney Museum of American Art, New York, ABD (Whitney Museum of American Art, 2002).
Galloway, birçok oyun sanatçıs1nın oyun modifikasyonu yöntemiyle çalıştıklarında genellikle birinci düzeyde, yani görsel temsil düzeyinde oyunu değiştirdiklerini belirtir. Bu türden müdahalelerin birçoğunda oyun sonunda oyun olmaktan çıkar ve sanatsal boyut oynanış ve etkileşimlilik oyunsal değil görsel-işitsel bir nitelik kazanır. Oyun sanatçllarının bir bölümü oyun teknolojisini kullanarak fakat sonunda eserin oyunsallığını azaltarak veya 
araçsallaştırarak kullansa da, bazı sanatçılar da oyunsallığı bir ifade kategorisi olarak seçerler. Örneğin bir başka sanatçı Kathleen Ruiz (2000) oyunsallığı törpülemeksizin yarattığı Bang Bang (you’re not dead?) ile birinci şahıs nişancı türü oyunlara yeni bir öneri getirerek zaten ölmüş olan sanal kişilerin ateş ederek canlandırıldığı bir oyun tasarlamış ve izleyiciyi yapitla oynayarak etkileşime davet etmiştir. Ruiz eserini 'etkileşimli multimedya oyun enstalasyonu' kategorisiyle sergilemiştir.

Galloway'in karşı-oyun (countergaming) kavramıyla açıkladığı muhalif oyun oynama pratiği, Grace’in eleştirel oyun (critical game) kavramıyla benzerlikler taşır. Karşı-oyunu tanımlarken Galloway, geleneksel oynanış ile muhalif oynanış arasında bir karşılaştırma yapar. Bu karşılaştırmaya dayalı tanımlamanın bir boyutu da 'oyunsal eyleme karşı radikal eylem' olarak verilmiştir: geleneksel oyun poetikasına karşı alternatif oynanış modları. Galloway’e (2006) göre, radikal eylem oynanışın eleştirisi anlamına gelir. Var olan ticari oyunların mod yapımı üzerinden düşünen Galloway, sadece görsel yüzeyi hedefleyen değişimlerin esas noktayı kaçırdığını, sanatçıların mod yaparken yeni eylem gramerleri yaratmaları gerektiğini, sadece yeni görsel gramerler ile yetinmemeleri gerektiğini belirtir. Sadece harita ve karakterlere yönelik olmayan, oynanışın mimari akışının yeniden yaratıldı̆̆ı örnekleri çağırır (Galloway, 2006, s.125-126).

Grace (2014)'in tasarım odaklı yaklaşımı ise, var olan ticari / geleneksel / ana akım oyunların modifikasyonlarından değil, doğrudan eleștirel oyun tasarımından yola çıkar ve bağımsız oyunların (independent / indie games) bir türü olarak eleştirel oyun tasarımını tanımlar. "Eleştirel oyunlar oyunların geleneksel oynanışlarını, oyuncu beklentilerini ve dijital oyunları tanımlayan çok sayıda öğe ve ilişkiyi eleştirir. Bunun içinde bunların içlerinde bulundukları toplumla olan ilişkisi de vardır" (Grace, 2014, s.1). Buradan yola çıkarak, oyun eleştirisi sadece yazı yazarak veya var olan oyunlara mod üreterek değil, aynı zamanda oyun tasarlayarak da yapılabilir. Tasarımcılar sadece dijital oynama statükosunu eleştirmezler, eleştirilerini sergileyen oyunlar geliştirebilirler.

Kültürel ürünler olarak dijital oyunların bağımsızlığı temelde onların üretim ve dağıtım ilişkilerine bağlı olarak ve ekonomi-politik açıdan tanımlanabilir. Buradaki bağımsızlık oyunun içeriği ve yaratacağı sanatsal etkisinden ayrı olarak oyunun yaratılma (üretim) ve oyuncusuna ulaşma koşullarıyla (dağıtım) ilişkilidir. Bağımsız oyun, eleştirel oyun, ciddi oyun, alternatif oyun veya sanat oyunu gibi farklı kategoriler bazen birbirleri yerine kullanılabilir veya bir oyunu tanımlamada bakış açısına göre değişken kullanışlılıklar sunan kavramlar olarak da karşımıza çıkabilirler. Örneğin, Parker sanat oyunlarını (artgames) bağımsız oyunların bir kategorisi olarak tanımlar. Sanat oyunlarının bağımsız oyunların daha geniş alanı içinde bir kategori veya bir biçim olarak ortaya çıkışı Passage (Rohrer, 2007), The Marriage (Humble, 2008), The Graveyard (Tale of Tales, 2008), Braid (Blow., 2008), Flower (thatgamecompany, 2009) ve Every Day The Same Dream (La Molleindustria, 2009) gibi oyunlar ile birlikte gerçekleşir (Parker, 2012: 41). Bu tür oyunları diğer oyunlardan, hatta sanat olmayan diğer bağımsız oyunlardan ayıran nitelikleri onların sahip olduğu daha üstün sanatsal ve kültürel etkiler olarak tanımlasa da, onların sanat olarak kabul görmeleri için bu resmileşmeyi onaylayacak bir sanat dünyası (art world) içinde değerlendirildiklerini de belirtir. Sanat dünyasını tanımlarken, Parker sosyolog Shyon Baumann’n (2007) kültürel bir nesne veya pratiğin sanat olarak kabul edilmesinde geçtiği süreci oluşturan üç etkenden faydalanır: (1) estetik anlamda kavranması için gerekli önkoşulları kuran alan dışı değişimler, bir 'olanak alanı' yaratılması, (2) üretimi, dağıtımı ve tüketiminin yeni bir bağlama oturtacak kurumsal yön değişimleri veya dönüşümler, (3) değer ve önemini üzerine atfedecek eleştirel söylemin ortaya çıkışı. Baumann’a göre, bu üç etken birlikte 
kültürel bir biçimin sanat olarak kuran ve sürdüren sanat dünyasını üretirler (Baumann, 2007; akt. Parker, 2012, s. 42). Buradan yola çıkarak Parker, tıpkı Hollywood sineması içinde sanat sineması kategorisinin ortaya çıkıs sürecinde olduğu gibi dijital oyunların da bu türden bir sürecin içinde olduğunu belirtir. Sanat oyunları için sanat dünyasını oluşturan ne türden kurumsal dönüşümlerin yaşandığını, öncül yapıların nasıl olanak alanları yarattığını ve Passage (2007) gibi bir oyunun eleştirmenler ve araştırmacılar tarafından nasıl estetik önemi olan bir iş olarak kategorize edilip üzerine düşünüldügünü ortaya koyar (2012).

Passage’ın yaratıcısı Rohrer, aslında sanat değil bilgisayar bilimi okumuş ve birkaç yıllık programlama deneyiminden sonra oyun tasarlamaya başlamıştır. İlk oyunu Transcend (2005)'i tasarlarken sanat olarak oyun yaratmaktan çok aklında yeni yapılar ve fikirler üretme itkisiyle hareket etmiştir. Transcend asla ölmeyen bir uzay gemisidir. Düşmanına ateş ettiği zaman bir müzik ortaya çıkar ve düşman geometrik parlak şekillere dönüşür. Oyun Rohrer’in deyişiyle, aynı zamanda prosedüral bir müzik-yaratım sistemidir. (Larson, 2016). Rohrer'in oyun tasarlayarak yaratmak istediği etki aynı zamanda Grace’in (2014) tanımıyla eleştirel bir etkidir, çünkü oyunların gelenekselleşmiş yapı, tür ve oynanışlarını, oyuncu beklentilerini ve dijital oyunları tanımlayan pek çok öğeyi tartışmaya açma amacıyla yaratılmıştır. Rohrer bir sonraki oyunu Cultivation (2007)'i tasarlarken oyunların sanat olarak düşünülebileceğini ilk kez duyumsamıştır. Charlie Kaufman, Alfred Hitchcock, Lars Von Trier gibi esin kaynakları olan Rohrer’e göre, bu kişilikler sadece yalın metaforlar üretmemiş, bir sanat yapıtından beklenmesi gereken eşsiz estetik deneyimler yaratmışlardır.

Passage’ı tasarladığı dönemde ise Rohrer otuz yaşına yaklaşmıştır, ikinci çocuğu dünyaya gelmek üzeredir ve yakın zamanda iyi bir dostunu kanser nedeniyle kaybetmiştir. Rohrer’in öznel yaşamsal deneyimi Passage’ın yaratacağı etkileşimli deneyimin merkezindedir. Burada artık, eleştirel oyun tasarımı yaklaşımı, doğrudan oyunu üreten kişinin öznel yaşam deneyimiyle birleşerek sanatsal etkiye ulaşır. Oyun boyunca oyuncu gittikçe yaşlanan bir erkek karakteri yönetir. Birkaç pikselden oluşan bu avatar oyunda daha aşağıda bulunan labirentlere girdikçe, hazine sandıkları artacak ve oyuncuya daha çok puan kazandıracaktır. Fakat bu labirentlerin içine çok girerse karakter bir daha çıkış yolunu bulamayabilir. Rohrer, "derine git ama çok da derinlere dalma" (Larson, 2016) mesajını vermekte ve bunu yaparken oyunun mekaniklerini ve sinırları kullanmaktadır. Oyuncu avatarın yolculuğunu kendisiyle karşılaşması halinde bilgisayar tarafından yönetilen bir kadın karakterle birleştirmeyi seçerse bu artık iki kişilik bir yolculuk haline gelir. Eşini bulan avatar artık eskisi gibi bazı alanlara ve hazine sandıklarına giremez. Oyunda daha yavaş ilerleyecektir ve yalnızken girebildiği labirentlere partneriyle giremeyecektir. Her ikisi de bir süre sonra yaşlanırlar. Kadın karakter bir süre sonra ölür ve erkek de eninde sonunda, ne kadar başarılı oynarsa oynasın, onun gibi ölecektir. Rohrer, oyunu Kasım 2007'de Montreal International Game Summit (MIGS) bünyesinde gerçekleştirilen bir oyun tasarım yarışmasında tasarlamıştır. Etkinliğin başlığı Gamma256'dır. Yarışmaya katılan bağımsız tasarımcılar en fazla 256 piksellik bir pencerede çalışabilirler. Passage ise 100 x 16 piksel çözünürlügünde (Parker, 2012, s.43), gerçekten de bir pasaja benzeyen ekran açıklığı içinde beş dakikayla sınırlı bir oyundur. 2012 yılında, MoMA’nın koleksiyonuna katılan Passage’dan sonra, Rohrer 2016 yılında Manhattan'da Wellesley College Davis Müzesi içinde The Game Wolds of Jason Rohrer başlı̆̆ 1 ile tek bir sanatçıya ait ilk geniş ölçekli video oyun sergisini açmıştır. Dickie’nin sanat tanımından bakıldığında, Rohrer artık bir sanat eseri ürettiği anlayışına katılan bir oyun tasarımcısıdır. Tasarladığı oyun belirli bir sanat dünyası içindeki kitle tarafından kavranmıştır. 2016 yılında açtığı sergi ile Rohrer sanat dünyası sistemini üretimini sunacağı bir çer- 
çeve olarak kullanmıştır. Bu sanat dünyası sadece çerçeve olarak sunduğu sergileme mekânlarıyla sınırlı da değildir. Bağımsız oyun üretimini destekleyen alternatif kurum, etkinlik, eleştiri ve söylem çerçevelerini de içermektedir ki, bağımsız oyun kategorisi içinde sanat oyunu türünün doğumunu müjdeleyen Passage da zaten bu türden bir etkinlik içinde hayata geçmiştir. Independent Games Festival, Indicade, Gamma gibi festival ve etkinlikler; The Independent Gaming Source, IndieGames.com, The Experimental Gameplay Project (Parker, 2012, s.46) gibi proje, kurum veya web siteleri sanat oyunları için olanaklar alanını genişletirken bu geniş çerçevenin, yani sanat dünyası sisteminin içindeki yerlerini alırlar.

Sanat dünyası bağlamı dışında, sanat yapıtının kendisine odaklanan Dantơnun sanat tanımından yola çıkıldığında sanat yapıtı olarak oyun (bu örnekte, özellikle de Passage), belki de en fazla, oyunun retorik (genellikle metaforik)boşluklar kullanması ve bu boşlukların izleyici (söz konusu oyun olunca elbette oyuncu ) katılımına bırakılması maddeleriyle sanat yapıtı tanımına yaklaşmaktadır. Rohrer, Passage’da metaforun oyunun mekanikleri olduğunu söyler (Larson, 2016). Bir oyunun yaratacağı estetik deneyim tam da o yapıtın oyun olarak tanımlanmasını sağlayan oyunun mekanikleri, sınırları, etkileşim biçimi ve kurallarından oluşur. Üstelik tüm bu nitelikleri, ana akım oyun endüstrisi içinde yaratılan birçok tanımlayıcı kural, oynanış, mekanik vb. niteliklerin özgün eleştirisini de kendi içinde taşıyarak yeniden kurar. Rohrer'in oyunları ise endüstriyel türlerin ve bu türlere bağlı olarak gelişmiş olan oynanış kalıplarının bir eleştirisidir öncelikle. Bu nedenle Rohrer, bir oyun tasarlayacağı zaman, bir strateji, teke tek dövüş veya nişancı oyunu yapmak üzere değil, ürettiği her oyunda yeni bir tür önerisi arayışında olduğunu belirtmiştir (Rohrer, 2015).

Oyunun sanatsal üretim sürecinin bir parçası olarak kullanıldığı oyun sanatından (game art) farklı olarak sanat oyunlarında (artgame) sanatsal ifade olanağı oyunsal niteliklere bağlı olduğundan, görsel-işitsel olan yüzeye eklenmiş etkileşim unsuru nedeniyle sanat yapıtı izleyicisi etkileşimciye dönüşür. Dolayısıyla sanat olarak oyunla etkileşime girmenin yöntemi onunla oynayabilmektir. Rohrer'in Davis Müzesi’nde açtı̆̆ sergide, izleyici sergide yer alan her oyun için oyunun amaçları ile strateji önerilerinin bulunduğu bir kullanma kılavuzuyla oyunları oynamaya davet edilir. Çünkü oyunun sanatsal ifade alanına sadece izleyerek girmesi mümkün değildir; oyunun mekanikleri, s1nırları ve kurallarını algılaması onun etkileşimine bağlıdır.

Bağımsız oyunlar için olanaklar alanı genişlerken, Rohrer gibi tek başına çalışan tasarımcıların yanında sanat oyunları üretmek ve var olan endüstriyel oyun kalıplarını sorgulamak isteyen görece küçük gruplar ve stüdyolar da sanat oyunları üretmeye başlamıştır. Bunlardan biri olan ve Auriea Harvey ve Michaël Samyn tarafından 2003 yılında kurulan Tale of Tales oyun geliștirme stüdyosunun temel amacı etkileşimli bilgisayar ortamını kullanarak sanat üretmektir. Tale of Tales tasarımcıları basit kontroller aracılığıyla şiirsel anlatıların içine girilebilecek anlamlı arayüzler tasarlamak istemişlerdir (Taleoftales.com, t.y.). Tale of Tales oyunları da kazanmak veya başarılı olmakla ilgili değildir ve yine tasarımları var olan türsel oynanış kalıplarını eleştirmeye yöneliktir. Bunlardan biri olan the Graveyard (Tale of Tales, 2008)'da oyun yaşlı bir kadını mezarlık boyunca yürütme üzerine kuruludur. Bu yürümenin sonucunda ulaşılacak amaç bir banka oturmak olacaktır. Oyunsal bir eylem olarak yürüme, ana akım oyunlarda çoğu zaman olabildiğince hızlı olması gereken, kimi zaman koşmayla veya engellerin üzerinden atlamayla karışık bir eylemdir. The Graveyard'daki avatar ise yürümekte zorlanan yaşlı bir kadındır ve oldukça yavaş yürümektedir. Oyuncu istese de avatarı daha hızlı yürütemez ve oyunun mekaniği aracılı̆̆ıyla yaşlı bir insanın bedensel sınırlarıyla tanışır. Birkaç adım attıktan sonra bir süre durup dinlenmezse sendeleyerek ilerlemeye başlar. Bir dijital 
oyun ve sanal bir karakter için oldukça kısa görünen mezarlık yolu oldukça yavaş kat edilir. Böylece ancak oyuncunun etkileşimi aracılığıyla varılabilecek sanatsal metafor yine oyunun mekaniğinin içinde gizlidir. Aynı metaforla oyun yine anaakım oyunların yerleştirdiği etkileşim pratiğine yaratıc1 / eleştirel bir tonda yaklaşmıştır.

Tale of Tales oyun stüdyosu dişında Flower (2009), Flow (2006) ve Journey (2012) gibi tasarladıkları oyunlarda ortak lirik bir üslup yaratarak sanat oyunu kategorisi ile ilişkilendirilen thatgamecompany de bu tartışma açısından önemli örnekler üretmiştir. Örneğin Flower'da oyuncu bir rüzgâr gibi uçarak karşısına çıkan çiçekleri açtırır. Oyunun amacı kentin gri betonlarıyla doğanın huzuru ve renkleri arasındaki kontrasttan yola çıarak oyuncuya verdiği şiirsel amaçla oyun dünyası boyunca çevreyi daha güzel bir yer haline getirmek üzerine kuruludur. thatgamecompany, Flower’ı tanımlarken "hareketteki şiir" ifadesini öne çıkarmış ve aslında oyunların şiire yaklaşabildiği yeni bir estetik form önerisinde bulunmuştur.

Fakat başka bir açıdan, politik ve eleştirel bir perspektiften oyun tasarlayan bir kolektif olarak "eğlence tiranlığına karşı radikal oyunlar” sunan La Molleindustria da sanat oyunu kategorisi ile ilişkilendirilen üretim odaklarından biri olarak durmaktadır. Üretimini radikal oyun olarak tanımlayan ve bağımsız bir kolektif olan La Molleindustria 2003’ten beri, anaakım eğlence endüstrisinin kısa, çevrimiçi ve bedava kılığında piyasaya sürdüğü sayısız oyuna karşı sanatsal çözümler üretmek amacıyla yola çıktıklarını açıklar. Bu amaçla, iş dünyasını eleştiren satirik simülasyonlar, emek ve yabancılaşma üzerine düşünmeye çağıran oyunlar, oynanabilir kuramlar vb. üretmişlerdir. (La Molleindustria, t.y). Tasarladıkları pek çok bağımsız oyun içinde Every Day the Same Dream örneğinde, birbirini sürekli tekrar eden aşamalardan oluşan gündelik yaşam eleştirisi üzerinden oyuncuda bir rahatlamadan çok onu kapitalist sistemdeki yabancılaşma teması üzerinden eleştirel bir perspektife yerleştirme, oyuncuyu eğlendirmek yerine onu rahatsız etme amacı vardır.

Oyunun diğer görsel-işitsel metinlerden farkı olan etkileşim ve sanatın eleştirellik ile olan sıkı bağı düşünüldüğünde, bir oyun metninin sanat olarak alımlanmasında oyunsal metnin sanatsal ifade alanı olarak oyuncu ile nasıl bir etkileşimlilik ilişkisi önerdiği ve bu ilişkide bulunan var olan etkileşim biçimlerine karşı geliştirilmiş- eleştirel boyutun varlığı iki farklı ölçüt olarak kabul edilebilir. Örneğin, nişancı türü oyunların etkileşimlilik biçimlerine eleştirel bir yaklaşımla bakan Grace, tasarlamış olduğu Bang! (1998) adlı oyunda oyuncu karşısına çıkan diğer karakterleri öldürür. Fakat bu eylemin sonucunda oyuna devam edebilmek için, öldürdüğü kişinin tüm yaşam öyküsünü öğrenmek zorunda kalır. Nişancı türünün önerdiği ve yaygınlaştırdığı bir etkileşim biçimi olarak öldür-geç eylem dizgesi böylece kırılır ve sorgulanmaya açılır.

\section{SONUÇ}

Literatür ana akımdan farklı düzey, aşama veya biçimlerde ayrılan birçok oyunu farklı kavramlar altında anlamlandırma girişimleriyle doludur. Eleştirel oyunlar, bağımsız oyunlar, sanat oyunları, alternatif oyunlar, karşı-oyun veya ciddi oyunlar, oyun tasarımının yapım süreç ve üretim - dağıtım ilişkileri, yapılan oyunun etkileşimlilik yapısı, oyunun hedeflediği oyuncu kitlesi veya hedeflediği oyun deneyimi / içeriği açısından ana akım endüstriyel türlerin dışında farklı bir türleştirme getirmiştir. Eğer bir tür olarak tanımlanacaksa sanat oyunu kategorisi de tüm bu öteki türler ile ilişki içindedir ve birlikte değerlendirilmeye açıktır. Bununla birlikte, nihayetinde bir oyunun meta olarak pazarda yer alması onun sanat olması önünde mutlaka bir engel olarak okunamaz. 
Parker da (2012, s. 42) sanat oyunlarını tanımlamanın zorluğunu gündeme getirmiştir: Sanat oyunlarının belirli görsel-işitsel estetiği büyük ölçüde çeşitlilik gösterir (the Graveyard ile Passage’ı karşılaştırın); tüm sanat oyunlarının tek bir yaratıcısı (author) bulunmaz (Everyday the Same Dream), tüm sanat oyunları mutlaka belirli bir varoluşsal temayı ifade etmeye çalışmaz (Flow); tüm sanat oyunları kısa değildir (Braid); bazı sanat oyunları ticaridir (Flower) ve tüm sanat oyunları bağımsız şirketler tarafından üretilmiş değildir (Lucidity). Aslında sanat oyunu terimi gevşek ve biçimsizdir, ve Parker amacının bu terimin sınırlarını çizmek veya türsel sınıflandırmasını sunmak olmadığını belirtir. Bunun yerine, çağdaş tür kuramını da dikkate alarak, sanat oyunlarını anlam ve değer üzerinden bir mücadele ve uzlaşının söylemsel inşa alanı olarak çerçeve içine almak daha verimli olacaktır. Ayrıca sanat oyunlarına, kavramın pragmatik olarak farklı kullanıcılar tarafından farklı sonlara açlan (Altman, 1999, akt. Parker, 2012) "aktif bir süreç" olması (Mittell, 2004, akt. Parker, 2012) boyutuyla, herhangi ortak bir karakteristiğe bağlı olmayan bir tür veya kültürel kategori olarak daha verimli bir biçimde yaklaşılabilir.

$\mathrm{Bu}$ araştırmanın içinde sanat ve oyunun ilişkilendiği farklı biçim ve yöntemlerden bazı alt biçim ve kategorilere ulaşmak mümkün olmuştur. Bunlardan ilki oyunu ve oyun oynanabilen medyayı sanat yapıtının üretim ve sergilenme sürecinde bir araç olarak kullanan yapıtlardır. Sanatçı Alison Mealey'nin, Unrealart (2005) projesi buna bir örnek olarak incelenmiştir. Alison Mealey bir oyun tasarlamamış fakat dijital oyun teknolojisini, etkileşimliliğini de sürece dahil ederek ve araçsallaştırarak etkileşimli ve oyunsal bir sanat deneyimi yaratmıştır.

Bir başka yöntem ise var olan bir oyuna mod yapımı ve/veya şifre kırma (hack'leme) gibi d1şarıdan müdahalelerle gerçekleştirilir. Bu yöntemlerin sonucunda Cory Arcangel'in Super Mario Clouds (2002) örneğinde olduğu gibi oyunun etkileşim niteliği yok edilerek sadece görsel-işitsel bir metne dönüştürülebildiği gibi; örneğin yine aynı sanatçının I Shot Andy Warhol (2000)'de yapmış olduğu gibi mod yapımı ile görsel-işitsel yüzeyde yapılan değişikliklere karşın oyunsallık, mekanikler ve etkileşim yapısı korunmuş olabilir. Arcangel seçtiği yöntem ve malzemeye müdahale biçimiyle hem video sanatının etkileşimli bir devamı niteliğinde tanımlanabilen oyun sanatı (game art), hem de sanat oyunu (art game) kategorilerinde üretmiş olması açısından önemli bir örnek olarak incelemeye dahil edilmiştir.

Üçüncü bir biçim ise daha önce üretilmiş bir oyunu bozarak veya araçsallaştırarak değil doğrudan bir oyun tasarlayarak sanat yapma yöntemidir. Burada oyun tasarımcısı veya bir tasarımcı grubu elindeki malzemeyi etkileşimli sanatsal bir metin yaratma amacıyla yola çıkar. Bu biçimde üreten kişi veya kolektifler için hem-görsel işitsel yüzey, hem anlatısal içerik, hem de etkileşim biçim ve türleri ile mekanikleri yaratıcı ve estetik kategoriler olarak birbirlerinden bağımsız olarak kullanabilmektedirler. Bu kişi veya kolektifler politik ve toplumsal eleştirel içerikten (Every Day the Same Dream), lirik dramaturjik üsluba (Flower, the Graveyard), etkileşimliliğin yaratıcı biçimlerinin üretiminden (Passage) var olan ana akım etkileşim biçimlerinin eleştirisine (Bang!) kadar farklı yöntem ve biçimlerle sanatsal ifade yaratımında bulunabilmektedirler. Dolayısıyla dijital oyun medyası ile sanat yapmak isteyen bir sanatçı için dijital oyun dilini oluşturan bu yüzeyleri hem üreteceği işin malzemesi olarak görebilmesi, hem eleştirel açıdan dönüştürülmeye açık içerikler biçiminde algllayabilmesi, hem de yeni biçimler ortaya koyabileceği bir yaratım sürecine giriş yapabilmesi açısından dijital oyunların birbiriyle de sürekli ilişki içinde bulunan anlatı, görselişitsel arayüz ve etkileşimlilik katmanlarını estetik kategoriler olarak kullanabilecek bir düzeyde tanıması gereklidir. 


\section{KAYNAKÇA}

Adams, E. (2006). Will Computer Games Ever Be a Legitimate Art Form, Journal of Media Practice 7 (1), 67-77. https:// www.tandfonline.com/doi/abs/10.1386/jmpr.7.1.67/1, (Erişim tarihi: 15.11.2018).

Antonelli, P. (2012). Video Games: 14 in the Collection, for Starters, https://www.moma.org/explore/inside_out/2012/11/29/ video-games-14-in-the-collection-for-starters/, (Erişim tarihi: 05.07.2018).

Arcangel, C. (Tasarimci). (2000). I Shot Andy Warhol. [Dijital oyun]. http://www.coryarcangel.com/things-i-made/2002002-i-shot-andy-warhol, (Erişim tarihi: 09.11.2018).

Arcangel, C. (Tasartmc1). (2002). Super Mario Clouds. [Oyun sanatt]. http://www.coryarcangel.com/things-i-made/2002001-super-mario-clouds, (Erişim tarihi: 09.11.2018).

Barrett, T. (2012). Why is That Art?, New York: Oxford University Press.

Bleszinski, C. ve Polge, S. (Tasartmcılar). (2004). Unreal Tournament [Dijital oyun]. ABD: Epic Games, Digital Extreme, Psyonix.

Brisbois, K. (Yazar / Yapımcl). (2007). I, Video Game [TV yayın]. Los Angeles: A World of Wonder Production, Discovery Networks International.

Crawford, C. (1997). The Art of Computer Game Design, Vancouver: Washington State University.

Folkerts, J. (2010). Playing Games as an Art Experience: How Videogames Produce Meaning through Narrative and Play, R. Daniel ve A Maj (Editörler), Emerging Practices in Cyberculture and Social Networking içinde (s.99-117). Amsterdam: Rodopi.

Galloway, A. (2006). Gaming: Essays on Algorithmic Culture, London: University of Minnesota Press.

Grace, L. (Tasarımcı). (1998). Bang! [Dijital oyun]. http://www.criticalgameplay.com/thegames.html, (Erişim tarihi: 09.11.2018).

Grace, L. (2014). Critical Games: Critical Design in Independent Games, Proceedings of DIGRA'da sunulan bildiri. https:// www.researchgate.net/publication/267153275_Critical_Games_Critical_Design_in_Independent_Games, (Erişim tarihi: 05.07.2018).

Iwatani, T. (Tasarımc1). (1984). Hogan's Alley. [Dijital oyun]. Japonya: Nintendo.

Jenkins, H. (2000). Art Form for the Digital Age, MIT Technology Review, http://web.stanford.edu/class/sts145/Library/ jenkins_artform.pdf, (Erişim tarihi: 05.07.2018).

Jonas, J. (2012). "Sorry MoMA, Video Games are not art", The Guardian Art and Design, https://www.theguardian.com/ artanddesign/jonathanjonesblog/2012/nov/30/moma-video-games-art, (Erişim tarihi: 15.11.2018).

Kroll, J. (2000). Emotion Engine? I Don't Think So, Newsweek, http://www.newsweek.com/emotion-engine-i-dont-thinkso-156675, (Erişim tarihi: 05.07.2018).

La Molleindustria (t.y.) About. http://www.molleindustria.org/blog/about/, (Erişim tarihi: 05.07.2018).

La Molleindustria (Tasarımci-Yayınc1). (2009) Every Day the Same Dream [Dijital oyun]. http://www.molleindustria.org/ everydaythesamedream/everydaythesamedream.html, (Erişim tarihi: 09.11.2018).

Lanchester, J. (2009). Is it Art?, London Review of Books, www.lrb.co.uk/v31/n01/john-lanchester/is-it-art, (Erişim tarihi: 05.07.2018).

Larson, S. (2016). Jason Rohrer and The Art of The Video Game, The New Yorker Culture Desk, https://www.newyorker. com/culture/culture-desk/jason-rohrer-and-the-art-of-the-video-game, (Erişim tarihi: 05.07.2018).

Ong, W. (2007). Sözlü Kültür, Yazılı Kültür, Sözün Teknolojileşmesi (4.baskı), (Çev: S. Postacıoğlu Banon), İstanbul: Metis. Özel Sağlamtimur, Z. (2010). Dijital Sanat, Anadolu Üniversitesi Sosyal Bilimler Dergisi, 10(3), 213-238.

Parker, F. (2012). An Art World for Artgames, Loading... The Journal of the Canadian Game Studies Association, 7(11), 41-60, http://journals.sfu.ca/loading/index.php/loading/issue/view/11, (Erişim tarihi: 15.11.2018).

Petersen, T. (2015). Generating Art from a Computer Game. An Interview with Alison Mealey, artificial.dk, http://www. artificial.dk/articles/alison.htm , (Erişim tarihi: 26.05.2017)

Robles, M. (2014). Video Games as an Art Form, ESSAI. (12), https://dc.cod.edu/essai/vol12/iss1/32, (Erişim tarihi: 19.11.2018).

Rohrer, J. (Tasarımc1). (2005). Transcend [Dijital oyun]. http://transcend.sourceforge.net/, (Erişim tarihi: 15.11.2018).

Rohrer, J. (Tasartmci). (2007). Cultivation [Dijital oyun]. http://cultivation.sourceforge.net/, (Erişim tarihi: 15.11.2018).

Rohrer, J. (Tasarımci). (2007). Passage [Dijital oyun]. http://hcsoftware.sourceforge.net/passage/, (Erişim tarihi: 09.11.2018).

Rohrer, J. (Konuşmaci). (2015). Jason Rohrer Interview, Game Over Man Podcast, https://www.youtube.com/ watch?v=oz1gImvXAUM, (Erişim tarihi: 06.06.2107).

Ruiz, K. (Tasarımc1). (2000). Bang Bang (you're not dead?). [Dijital oyun]. http://homepages.rpi.edu/ ruiz/projects/Bang/ 
Bang.html, (Erişim tarihi: 15.11.2018).

Sezen, D. (2013). Bir Sanatsal İfade Aracı Olarak Dijital Oyunlar, İstanbul Üniversitesi İletişim Fakültesi Dergisi, II (45), 129-147.

Smuts, A. (2005). Are Video Games Art?, Contemporary Aesthetics, 3, https://www.contempaesthetics.org/newvolume/ pages/article.php?articleID=299, (Erişim tarihi: 05.07.2018).

Tale Of Tales (t.y.). About. http://tale-of-tales.com/about.php, (Erişim tarihi: 05.07.2018).

Thatgamecompany (Tasarımc1 - Yayınc1). (2006). Flow [Dijital oyun]. https://www.jenovachen.com/flowingames/flowing. htm, (Erişim tarihi: 15.11.2018).

Thatgamecompany (Tasarımcı - Yayınc). (2009). Flower [Dijital oyun]. http://thatgamecompany.com/flower/, (Erişim tarihi: 15.11.2018).

Thatgamecompany (Tasarımcı - Yayıncı). (2012). Journey [Dijital oyun]. https://www.gamesknit.com/journey-versionfor-pc/, (Erişim tarihi: 15.11.2018).

Wands, B. (2006) Dijital Çağın Sanatı, (Çev: O. Akınhay) İstanbul: Akbank Sanat.

Whitney Museum Of American Art. (2002). Görsel 1. Arcangel, "Super Mario Clouds”, Boyutları Değişken Oyun Enstalasyon, Elle Şifresi Kırılmış Süper Mario Kardeşler Kartuşu Ve Nintendo NES Video Oyun Sistemi, 2002, Whitney Museum of American Art, New York, ABD, http://collection.whitney.org/object/20588, (Erişim tarihi: 26.05.2017). 